\title{
Eicosanoid profile of healing colon anastomosis and peritoneal macrophages in the rat
}

\author{
A C van der Ham, W J Kort, A M Bijma, F J Zijlstra, M A Vermeer, J Jeekel
}

\begin{abstract}
Because intraperitoneal administration of prostaglandin $\mathbf{E}_{2}\left(\mathbf{P G E}_{2}\right)$ has a negative influence on the healing of colonic anastomosis, the production of eicosanoid products in the healing rat colon after resection and anastomosis was studied using high performance liquid chromatography. Normal colonic tissue metabolises small amounts of arachidonic acid into cyclo-oxygenase and lipoxygenase products. After construction of an anastomosis, however, there is increased production of lipoxygenase products, while cyclooxygenase activity remains low. Increased amounts of $\mathrm{PGE}_{2}$ and other cyclo-oxygenase products are not produced after anastomosis of the colon and probably do not play a major role in uncomplicated healing of the large intestine in the rat. During the first eight days of repair in the anastomosed colonic tissue, a statistically significant increase in 12hydroxyeicosatetraenoic acid (12-HETE) production was found compared with control colon tissue $(p=0.001)$. At the same time peritoneal macrophages from these rats showed increased 12-HETE production. Eicosanoid synthesis of peritoneal macrophages resembled eicosanoid synthesis of anastomosed colon taken from the same rat indicating that 12-HETE, in particular, may be of macrophage origin.
\end{abstract}

Leakage of colonic and rectal anastomoses is a major complication after large intestine surgery, but the reported incidences vary greatly. Using routine barium enema studies, leakage was detected in up to $50 \%$ of patients who underwent anterior resection of the sigmoid colon and rectum. ${ }^{1}$ Clinically evident anastomotic leakage is associated with increased mortality and morbidity. ${ }^{2}$ There are many factors that contribute to either healing or leakage of an anastomosis: blood supply, oxygen tension, type of sutures, bowel preparation, surgical technique, tension on the anastomosis, and patient condition. ${ }^{2-4}$ All these factors influence the formation of connective tissue, the key product in wound healing.

Halsted $^{4}$ first showed the importance of the submucosal connective tissue in relation to anastomotic healing in 1887 . The quantity and quality of collagen in the submucosal layer of the intestinal wall determines the strength of the intestine and its capacity to hold sutures.

Many studies on collagen metabolism in intestinal anastomoses have been performed using rat models. For the first three days after intestinal anastomosis a reduction in the suture holding capacity was found.$^{67}$ During this early phase there was a significant decrease in the collagen concentration in the colon. ${ }^{89}$ This reduction in collagen content is highest just proximal to the anastomosis and can also be detected further away. After the third day, a rapid increase in strength is observed. Collagen production is increased from the very first day after operation and is highest in the vicinity of the anastomosis. ${ }^{10}$ Comparison of net amounts with the rate of synthesis indicates an increased breakdown of collagen. ${ }^{10}$

Local degradation of mature collagen may be the cause of the severing of sutures resulting in breakdown of the anastomosis. ${ }^{81}$ When collagenase inhibitor was given a significant increase in the bursting pressure of a colonic anastomosis was found in rabbits. ${ }^{12-14}$

Factors that directly inluence the formation of collagenase are infection and inflammation. As expected high collagenase activity was found in the colonic mucosa in colitis and around infected anastomoses. ${ }^{11}$ Is Inflammatory cells, for example macrophages, are known to produce collagenase after stimulation by bacteria. ${ }^{16}$ This collagenase production is dependent on prostaglandin $\mathrm{E}_{2}$ $\left(\mathrm{PGE}_{2}\right)$. Rats treated with $\mathrm{PGE}_{2}$ showed a significantly weaker anastomosis of the colon on day three than control rats, but this finding was reversed by the addition of indomethacin, a prostaglandin synthesis inhibitor. ${ }^{17}$

To evaluate the possible role of prostaglandins in uncomplicated healing of colonic anastomosis, we decided to measure eicosanoid synthesis in colon tissue and peritoneal macrophages. Peritoneal macrophages were studied as a possible source of the eicosanoid products.

\section{Material and methods}

Male inbred Wag/Rij rats weighing 200-300 g were used. The animals had free access to a standard diet (Hope Farms, Woerden, The Netherlands) and to water before and after surgery. Anaesthesia was induced by ether inhalation. After median laparotomy, the colon was divided $2.5 \mathrm{~cm}$ above the peritoneal reflection and a standardised left colonic resection of $1 \mathrm{~cm}$ was carried out with end to end anastomosis. The end to end anastomosis was made with 12 interrupted inverting sutures through all layers, using $7 \times 0$ polypropylene (Prolene, Ethicon, West Germany). On days 1, $2,4,8$, and 16 the animals were sacrificed to obtain peritoneal macrophages and colonic tissue. Peritoneal macrophages and colonic tissue from rats who had not undergone surgery were used as controls.

\section{PREPARATION OF PERITONEAL}

MACROPHAGES

Peritoneal cells were collected during ether anaesthesia by lavage with $50 \mathrm{ml}$ of cold phos-
Rotterdam, The Netherlands.

Accepted for publication

18 September 1989 


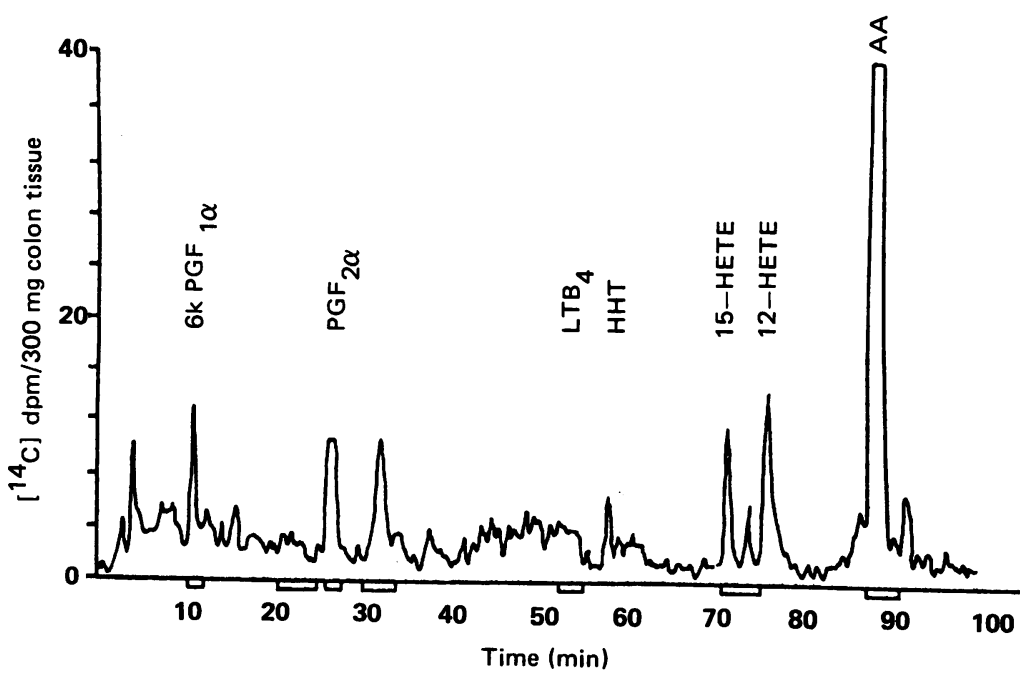

Figure 1: Reversed phase HPLC separation of eicosanoids produced by chopped normal rat colon tissue after loading with $\left({ }^{14} \mathrm{C}\right)$ arachidonic acid and $\mathrm{Ca}^{++}$-ionophore $\mathrm{A} 23187$ challenge. Bars under time trace indicate peak width of both $\left({ }^{4} \mathrm{C}\right)$ labelled metabolites and $\left({ }^{3} \mathrm{H}\right)$ labelled standards. phate buffered saline (PBS) (pH 7·2). The fluid containing the cells was centrifuged for 10 minutes at $250 \mathrm{~g}$. The cells were resuspended in $5 \mathrm{ml}$ cold PBS, washed once, and counted. The peritoneal macrophages were isolated from granulocytes by centrifugation and sedimentation on a Percoll gradient (Pharmacia, Sweden)..$^{18}$

\section{PREPARATION OF COLON TISSUE}

After peritoneal lavage, the abdomen was reopened and the colon was dissected free from the mesentery. Two segments of colonic tissue, each weighing $300 \mathrm{mg}$, were taken from the ascending and the descending colon. The latter, which contained the anastomosis, was removed, rinsed of blood with PBS, and immediately put on ice. The tissue was minced using a McIlwain tissue chopper and suspended in $5 \mathrm{ml} \mathrm{PBS}$.

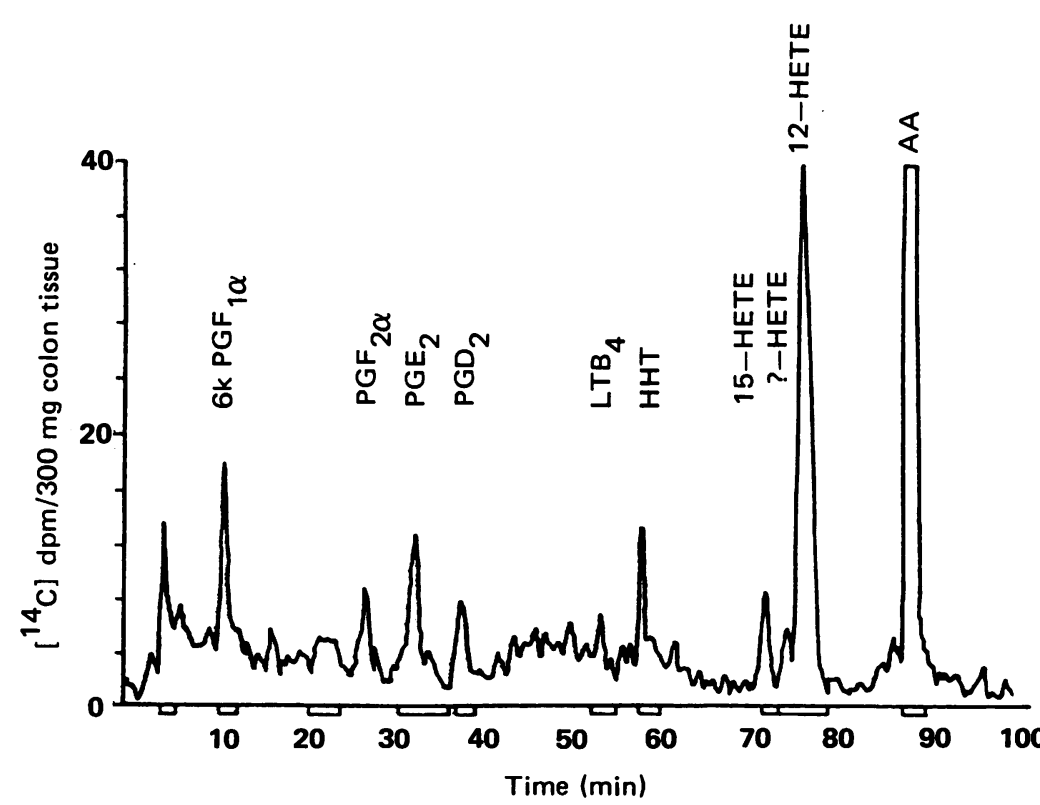

Figure 2: Reversed phase HPLC separation of eicosanoids produced by chopped rat colon tissue one day after resection and anastomosis, in response to $\left({ }^{14} \mathrm{C}\right)$ arachidonic acid and $\mathrm{Ca}^{++}$ionophore A23187. Bars under time trace indicate peak width of both $\left({ }^{14} \mathrm{C}\right)$ labelled metabolites and $\left({ }^{3} \mathrm{H}\right)$ labelled standards.

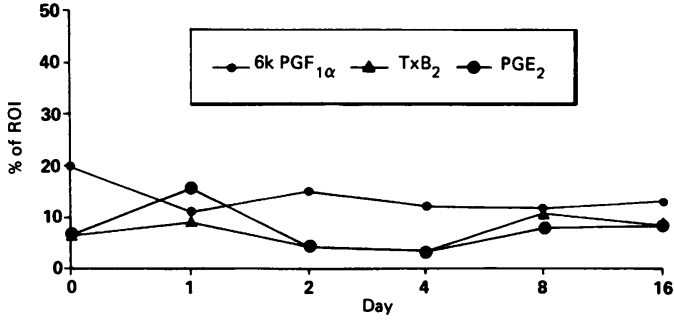

Figure 3: Synthesis of prostanoids by chopped rat colon tissue after resection and anastomosis. Values are generated from reversed phase HPLC and given as percentage of the total region of interest $(R O I)$. Each time point represents two tissue samples in one rat. Single measurements were performed.

\section{DETERMINATION OF EICOSANOIDS}

Peritoneal macrophages and colonic tissue cells were incubated with $0.5 \mu \mathrm{Ci}\left(1-{ }^{14} \mathrm{C}\right)$ arachidonic acid and $2 \mu \mathrm{M}$ calcium ionophore A23187 (Sigma, USA) in $10 \mathrm{ml}$ Krebs Henseleit buffer at $37^{\circ} \mathrm{C}$ for 10 minutes. After this, known amounts of $\left[{ }^{3} \mathrm{H}\right]$-labelled standards (thromboxane $B_{2}$, $\mathrm{PGE}_{2}$, leukotriene $\mathrm{B}_{4}$, and 12-hydroxy-5,8,10, 14,-eicosatetraenoic acid (12-HETE)) were added and the incubation sample was centrifuged for two minutes at $2800 \mathrm{~g}$ at $4^{\circ} \mathrm{C}$. The supernatant was put in a SepPak $\mathrm{C}_{18}$ cartridge (Waters Associates, USA). The $\mathrm{C}_{18}$ cartridge was prewashed with $10 \mathrm{ml}$ of absolute ethanol and 10 $\mathrm{ml}$ of water. The ethanol eluate was dried with a Savant Speed Vac concentrator, combined with a vacuum pump. The pellet was dissolved in $250 \mu \mathrm{l}$ of methanol and filtered through a Gelman LC3a 0.45 $\mu \mathrm{m}$ filter (Gelman Sciences, USA) into a high performance liquid chromatography (HPLC) microvial. Of this sample, $100 \mu \mathrm{l}$ was injected onto a Zorbax $\mathrm{C}_{18}$ HPLC column $(250 \times 4.6 \mathrm{~mm}$ id; Dupont, USA). Reversed phase chromatography was performed with a solvent system consisting of $\mathbf{3 0 \%}$ acetonitrile in water, acidified with acetic acid to $\mathrm{pH} 2 \cdot 4$, and a flow of $1 \mathrm{ml} / \mathrm{min}$ at $37^{\circ} \mathrm{C}$. After 35 minutes the acetonitrile was increased to $49 \%$ in 13 minutes and maintained for 40 minutes. Arachidonic acid was eluted at $100 \%$ acetonitrile. HPLC was performed using a Hewlett-Packard 1084B (USA) liquid chromatograph consisting of a double head pump, a temperature controlled column compartment, and a variable volume injector. An on-line Berthold LB 506c radioactivity monitor (Wildbad, West Germany) was controlled by the HP 1084B terminal.

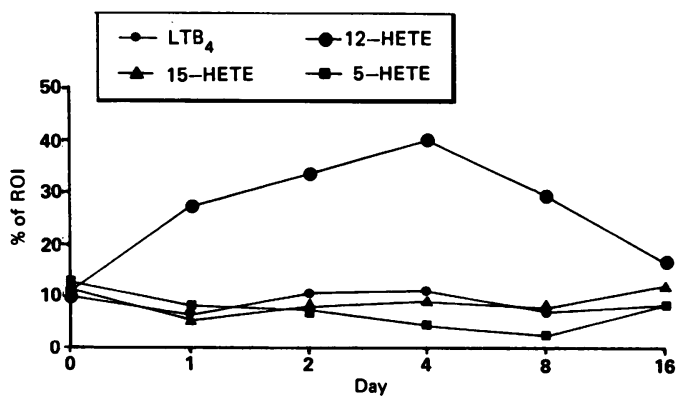

Figure 4: Synthesis of lipoxygenase products by chopped rat colon tissue after resection and anastomosis. Values are generated from reversed phase HPLC and given as percentage of the total region of interest $(R O I)$. Each time point represents two tissue samples in one rat. Single measurements were performed. 


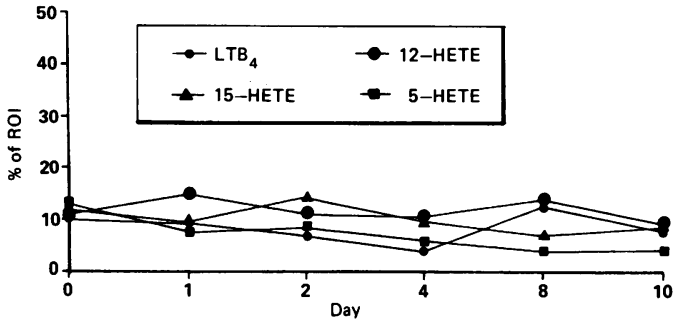

Figure 5: Synthesis of lipoxygenase products by chopped rat colon tissue proximal to colon anastomosis after resection and anastomosis of the left colon. Values are generated from reversed phase HPLC and given as percentage of the total region of interest (ROI). Each time point represents two tissue samples in one rat. Single measurements were performed.

\section{STATISTICAL METHODS}

Statistical analyses were performed using multiand univariate analysis of variance (Anova). The null hypothesis of no difference is rejected at the value of $0 \cdot 05$. However, in the case of findings by chance, Bonferroni's inequality implies that the value of significance is $p=0.0125 .^{19}$

\section{Results}

All animals survived the operation. The profile of eicosanoids synthesised by normal rat colon is shown in Figure 1. Normal rat colon tissue metabolises a small portion only of the exogenous arachidonic acid; approximately $15 \%$ is converted into a number of eicosanoids from which small peaks of 6 keto $\mathrm{PGF}_{1 \alpha}$, $\mathrm{PGF}_{2 \alpha}, \mathrm{LTB}_{4}, \mathrm{HHT}$ (12-hydroxy-5,8,10heptadecatrienoic acid), 15-HETE, 12-HETE, and 5-HETE can be detected. Of the lipoxygenase products, the 12-HETE is synthesised most prominently $(40 \%)$. On day 1 after surgery the HPLC profile of the segment of colon containing the anastomosis had changed drastically: 6 keto $\mathrm{PGF}_{1 \alpha}, \mathrm{PGE}_{2}, \mathrm{PGD}_{2}$, and $\mathrm{HHT}$ tended to increase, but not significantly; 15 HETE had decreased; but there was a fourfold increase in production of 12-HETE (Fig 2).

In Figures 3 and 4 the values of the lipoxygenase products $\mathrm{LTB}_{4}, 15-\mathrm{HETE}, 12-\mathrm{HETE}$,

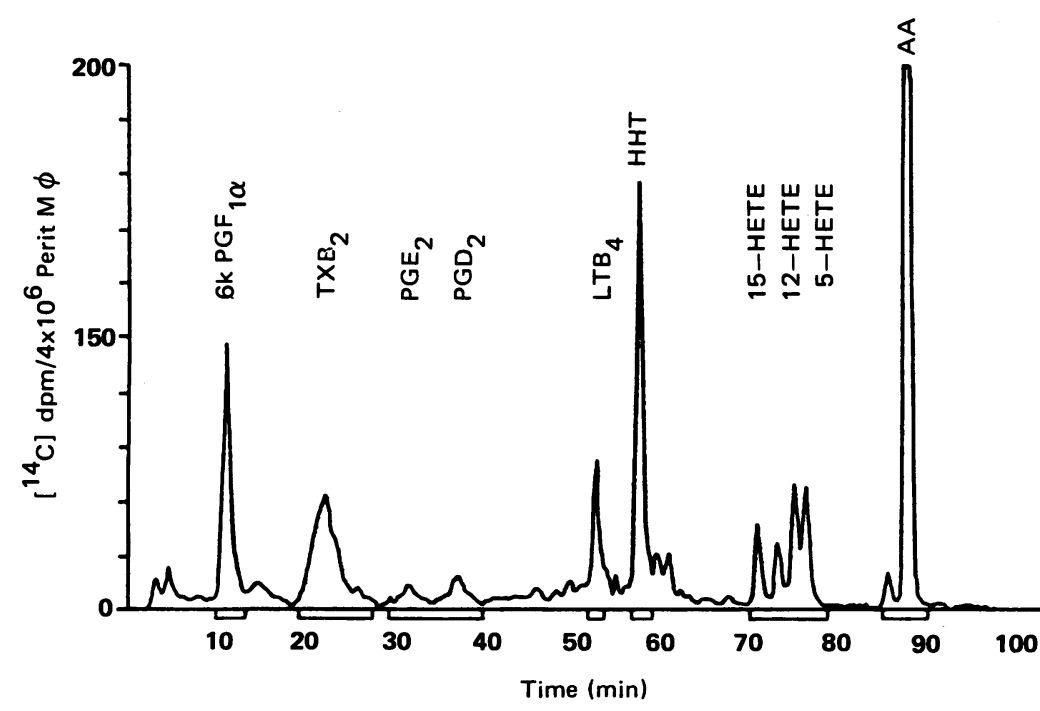

Figure 6: Reversed phase HPLC separation of eicosanoids produced by rat peritoneal macrophages obtained 1 day after colonic resection and anastomosis, in response to $\left({ }^{14} \mathrm{C}\right)$ arachidonic acid and $\mathrm{Ca}^{++}$-ionophore A23187. Bars under time trace indicate peak width of both $\left({ }^{1+} \mathrm{C}\right)$ labelled metabolites and $\left({ }^{3} \mathrm{H}\right)$ labelled standards.

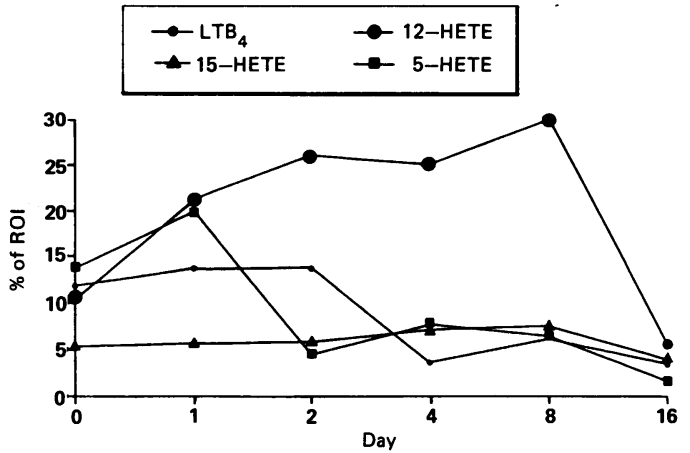

Figure 7: Synthesis of lipoxygenase products by rat peritoneal macrophages after resection and anastomosis of the left colon. Values are generated from reversed phase HPLC and given as percentage of the total region of interest $(R O I)$. Each time point represents two tissue samples in one rat. Single measurements were performed.

and 5-HETE and prostanoids 6 keto $\mathrm{PGF}_{1 \alpha}$, $\mathrm{TxB}_{2}$, and $\mathrm{PGE}_{2}$ as calculated from the HPLC profiles are given as percentage of region of interest. The graph clearly shows the increased 12-HETE synthesis, reaching maximal differences from basic values on day 4 (statistically significant, $p<0.001)$. On day 16, 12-HETE synthesis in colonic anastomosis tissue had returned to normal values. In the segments taken proximal to the anastomosis only minor changes in production of eicosanoids occurred (Fig 5).

Eicosanoid synthesis by peritoneal macrophages shows a shift from cyclo-oxygenase to lipoxygenase products on day 1 compared with day 0 . An example of an HPLC profile of eicosanoids synthesised by peritoneal macrophages is shown in Figure 6. Like colonic tissue at the site of the anastomosis, peritoneal macrophages from the same rat show a noticeable lipoxygenase activity, starting on day 1 (Fig 7). On day 8 the 12-HETE production is maximal. The other lipoxygenase products show minor variation.

\section{Discussion}

This study shows that normal rat colonic tissue metabolises a small portion only of exogenous arachidonic acid into cyclo-oxygenase and lipoxygenase products. The 6 keto PGF $_{1 \alpha}$ was the major cyclo-oxygenase product but 12-HETE was the major lipoxygenase product detected. These findings agree with reports showing that the mucosa of normal rat intestine metabolises a very small portion only of exogenous arachidonic acid into cyclo-oxygenase products. ${ }^{20}$ Although the proportion metabolised is still small, the profile of products changes after resection and anastomosis of the colon: our results show a sharp increase in 12-HETE production, whereas cyclo-oxygenase products show only minor increase.

$\mathrm{PGE}_{2}$ administered intraperitoneally has been reported to have an adverse influence on the healing of colonic anastomosis in the rat. ${ }^{17}$ Our results show, however, that $\mathrm{PGE}_{2}$ and other cyclo-oxygenase products are not produced in excess after anastomosis of the colon and probably do not play a major role in uncomplicated healing of the large intestine in the rat. 
The origin and possible role of 12-HETE in wound healing are interesting issues. After tissue injury such as surgery, phospholipase $A_{2}$ is activated. ${ }^{21}$ This phospholipase releases arachidonic acid from the phospholipid stores in cell membranes. The liberated arachidonic acid is the substrate of eicosanoids. The type of eicosanoids synthesised may vary greatly between different cell types. ${ }^{22}$ During the first 24 hours after the construction of an anastomosis, the colonic wound is infiltrated by neutrophil granulocytes, after which eosinophils and macrophages gradually occur. ${ }^{23} 5$-Lipoxygenase products, $\mathrm{LTC}_{4}$ and $\mathrm{LTB}_{4}$, are produced in high amounts by all cell types mentioned, however, platelets synthesise mainly 12-HETE. ${ }^{24}$ This means that basically any of these cell types may be responsible for the observed alteration of eicosanoid synthesis in our study.

The primary influx of granulocytes, which produce, in particular, the chemotactic leukotriene $\mathrm{B}_{4}$, could be responsible for the $\mathrm{LTB}_{4}$ formation. During the early phase of wound healing, however, we did not observe a significant increase in this product. Moreover, the pattern of the lipoxygenase arachidonic acid metabolites did not resemble that of stimulated peripheral blood neutrophils. It is possible that thrombocyte contamination of the sample tissue occurred, but in this case one would also expect high $\mathrm{TxB}_{2}$ and $\mathrm{HHT}$ values and these were not noted in our study.

The results of this study show that normal colonic tissue does not itself have a significant lipoxygenase activity. Using a rat colitis model, $\mathrm{LTB}_{4}$ and 5-HETE were found in the mucosa of the large intestine, whereas in normal rat colon mucosa no lipoxygenase products were found ${ }^{20}$ The enhanced intestinal prostanoid synthesis in inflammatory bowel disease is thought to come from stimulated local mononuclear cells. ${ }^{25}$

This leads us to our final candidate, the macrophage. Macrophages are a known source of lipoxygenase metabolites, 12-HETE being the major one produced. This strongly suggests that the increase in 12-HETE found in our study is of macrophage origin and that macrophages play an important role in colonic anastomosis healing from as early as day 1 after surgery. This is in contrast with the results of other investigators who found that in rat colonic anastomosis, monocytes are not seen for 48 hours. ${ }^{26}$ To learn more about the presence of macrophages in the first few days after anastomosis more advanced studies, for example, using monoclonal antibodies against macrophages, are needed.

There is substantial evidence that some arachidonic acid metabolites cause or enhance the signs of inflammation, the first phase of wound healing. ${ }^{22}$ Compared with other eicosanoids, there is little information on the function of 12-HETE. Although less active than LTB $_{4}, 12$-HETE also has chemotactic activity on inflammatory cells. ${ }^{27}$ The products of the lipoxygenase pathway stimulate proliferation of epidermal cells and lymphocytes. ${ }^{28}$ Topical administration of $\mathrm{LTB}_{4}$ and 12-HETE stimulates epidermal proliferation. ${ }^{29}$ In addition, it was found that monoHETEs, including 12HETE, exert modulatory actions on arachidonic acid metabolism in peritoneal macrophages. ${ }^{30}$ Interestingly, 12-HETE inhibited synthesis of $\mathrm{PGE}_{2}$. The mentioned properties of 12-HETE may indicate a possible role in wound healing. From this information, however, we cannot deduce whether 12-HETE plays a significant role in colon healing or whether it is a rather aspecific finding. As macrophages are a known source of collagenase, their activity in the healing colon may cause collagen breakdown in the early phase of wound repair.

It is evident that the raised lipoxygenase activity after the construction of a colonic anastomosis needs further study to determine whether other species and humans show the same phenomena. Such a study on the effect of lipoxygenase inhibition on intestinal wound healing is currently being undertaken.

We thank Prof $\mathbf{R}$ van Strik, Department of Biostatistics, Erasmus University Rotterdam, for valuable advice on statistical analysis.

1 Goligher JC, Graham NG, de Dombal FT. Anastomotic dehiscence after anterior resection of rectum and sigmoid. dehiscence after anterior $\mathrm{rese}$

2 Fielding LP, Stewart-Brown S, Blesovsky L, Kearny G Anastomotic integrity after operations for large-bowe cancer: a multicentre study. $\mathrm{Br} \mathrm{Med} \mathcal{F} 1980 ; 281: 411-4$.

3 Shandall A, Lowndes R, Young HL. Colonic anastomotic healing and oxygen tension. Br $\mathcal{Y}$ Surg 1985; 72: 606-9.

4 Halsted WS. Circular suture of the intestine - an experimental study. Am f Med Sci 1887; 94: 436-61.

5 Gottrup F. Healing of incisional wounds in stomach and duodenum: collagen distribution and relation to mechanical strength. Am $\mathcal{F}$ Surg 1981; 141: 222-7.

6 Jönsson K, Jiborn $\mathrm{H}$, Zederfeldt $\mathrm{B}$. Breaking strength of small intestinal anastomosis. Am $\mathcal{F}$ Surg 1983; 145: 800-3.

7 Jönsson $\mathrm{K}$, Jiborn $\mathrm{H}$, Zederfeldt $\mathrm{B}$. Changes in collagen content of the small intestinal wall following anastomosis. Am 7 Surg 1985; 150: 315-7.

8 Wise L, McAlister W, Stein T, Schuck P. Studies on the healing of anastomoses of small and large intestines. Surg Gynecol Obstet 1975; 141: 190-4.

9 Jiborn H, Ahonen J, Zederfeldt B. Healing of experimenta colonic anastomoses: III. Collagen metabolism in the colo after left colon resection. Am $\mathcal{F}$ Surg 1980; 139: 398-405.

10 Jönsson $\mathrm{K}$, Jiborn $\mathrm{H}$, Zederfeldt B. Collagen metabolism in small intestinal anastomosis. Am $\mathcal{F}$ Surg 1987; 154: 288-91.

11 Hawley PR. Causes and prevention of colonic anastomotic breakdown. Dis Colon Rectum 1973;16:272-7.

12 Delaney PV, Lalor D, Fitzgerald P, O'Malley E. The use of 'collagenase inhibitor' in prevention of large bowel anasto'collagenase inhibitor' in prevention of lar

13 Delaney $P$, Lalor D. Enzyme inhibition in colorectal surgery. Br F Surg 1976; 63: 23-4.

14 Högström H, Haglund U, Zederfeldt B. Beneficial effect on intestinal anastomosis of $S-2441$, a synthetic kallikrein-kinin antagonist: experimental studies in the rat. Am $\mathcal{F}$ Surg 1985 150: $312-3$

15 Yamakawa T, Patin CS, Sobel S, et al. Healing of coloni anastomoses following resection for experimental 'diverticulitis'. Arch Surg 1971; 103: 17

16 Wahl LM, Walh SM, Mergenhagen SE, Martin GR Collagenase production by endotoxin-activated macrophages. Proc Natl Acad Sci USA. 1974; 71: 3598-601.

17 Brennan SS, Foster ME, Morgan A, Leaper DJ. Prostaglandins in colonic anastomotic healing. Dis Colon Rectum 1984; 27 : 723-5.

18 Ouwendijk RJTh, Zijlstra FJ, Wilson JHP, Vincent JE, Bonta IL. Production of leukotrienes and prostaglandins by human ascites cells. Eur $\mathcal{F}$ Clin Invest 1985; 15: 327-31.

19 Ingelfinger JA, Mosteller F, Thibodeau LA, Ware JM Biostatistics in clinical medicine. New York: MacMillan Publishing, 1987.

20 Sharon P. Inflammatory bowel disease: treatment modalitie and mucosal prostaglandin/leukotriene formation. In Domschke W, Dammann HG, eds. Prostaglandins and leukotrienes in gastro-intestinal diseases. Berlin: SpringerVerlag, 1988: 273-83.

21 Piper P, Vane JR. The release of prostaglandins from the lung and other tissues. Ann NY Acad Sci 1971; 180: 363-85.

22 Williams KI, Higgs GA. Eicosanoids and inflammation. F Pathol 1988; 156: 101-10.

23 Hesp WLEM, Hendriks Th, Schillings PHM, Lubbers EJC, de Boer HHM. Histologic features of wound repair: a comparison between experimental ileal and colonic anastomoses. Brf Exp Pathol 1985; 66: 511-8.

24 Lorenzet R, Niemetz J, Marcus AJ, Broekman MJ. Enhancement of mononuclear procoagulant activity by platelet 12 ment of mononuclear procoagulant activity by platelet 12 25 Zifroni A, Treves AJ, Sachar DB, Rachmilewitz D. Prosta- 
noid synthesis by cultured intestinal epithelial and mononuclear cells in inflammatory bowel disease. Gut 1983; 24 659-64.

26 Högström H, Bondeson L, Haglund U. Neutrophil-induced decrease in wound margin strength after intestinal anastomosis; influence on collagen and mechanisms of granulocyte

27 Goetzl EJ, Woods JM, Gorman RR. Stimulation of human eosinophil and neutrophil polymorphonuclear leukocyte chemotaxis and random migration by 12-1-hydroxy-5,8,10 14-eicosatetraenoic acid. $\mathcal{F}$ Clin Invest 1977; 59: 179-83.
28 Gualde N, Atluru D, Goodwin JS. Effect of lipoxygenase metabolites of arachidonic acid on proliferation of human T cells and T cell subsets. F Immunol 1985; 134: 1125-9.

29 Chan CC. Duhamel L, Ford-Hutchinson A. Leukotriene B and 12-hydroxyeicosatetraenoic acid stimulate epidermal proliferation in vivo in the guinea pig. 7 Invest Dermatol proliferation in

30 Chang J, Lamb B, Marinari L, Kreft AF, Lewis AJ. Modulation by hydroxyeicosatetraenoic acids (HETEs) of arachidonic metabolism in mouse resident peritoneal macrophages. Eur F Pharmacol 1985; 107: 215-22. 